\title{
AVALIAÇÃO DA ESTABILIDADE E ADAPTABILIDADE DE GENÓTIPOS DE FEIJOEIRO (Phaseolus vulgaris L.) BASEADA NA ANÁLISE MULTIVARIADA DA "PERFORMANCE" GENOTÍPICA
}

\author{
Evaluation of the stability and adaptability of genotypes of common beans \\ (Phaseolus vulgaris L.) through multivariate analysis of genotype performance \\ Eliana Francischinelli Perina ${ }^{1}$, Cássia Regina Limonta Carvalho ${ }^{2}$, Alisson Fernando Chiorato ${ }^{2}$, \\ João Guilherme Ribeiro Gonçalves ${ }^{3}$, Sérgio Augusto Morais Carbonell ${ }^{2}$
}

\begin{abstract}
RESUMO
Neste estudo, objetivou-se avaliar a estabilidade e a adaptabilidade de genótipos de feijoeiro, cultivados em diferentes ambientes, por meio da análise multivariada da performance genotípica, empregando-se os teores de água, o valor protéico e os parâmetros de qualidade tecnológica dos grãos (porcentagem de absorção de água antes e após o cozimento, tempo de cozimento, porcentagem de grãos inteiros, expansão volumétrica e sólidos solúveis totais no caldo), em conjunto com a produtividade média dos genótipos cultivados em diversos ambientes, visando a identificar as linhagens e/ou cultivares mais estáveis e adaptadas para o conjunto de caracteres de importância para a cadeia produtiva do feijoeiro. Para tanto, foram avaliados 19 genótipos de feijoeiro pertencentes aos ensaios de VCU (Valor de Cultivo e Uso) 2005/2006/2007 de grãos dos grupos comerciais carioca e preto para o estado de São Paulo. Os resultados obtidos pela análise multivarida para a o conjunto das três épocas de semeadura reportaram o genótipo Gen 96A98-15-3-52-1 e a cultivar IAC-Alvorada como estáveis, responsivas à melhoria dos ambientes e tolerantes nos ambientes desfavoráveis. Por meio dos resultados obtidos, conclui-se que a análise de estabilidade e adaptabilidade multivariada proposta por Carneiro (1998), baseadas em Lin \& Binns (1988), mostra-se eficiente e simples para a avaliação do desempenho genotípico das cultivares, além de apresentarem unicidade do parâmetro para estimar a adaptabilidade à ambientes favoráveis e desfavoráveis, e simplicidade na interpretação dos resultados.
\end{abstract}

Termos para indexação: Produtividade, qualidade tecnológica, valor protéico, interação genótipo x ambiente.

\begin{abstract}
The purpose of this research was to evaluate the stability and adaptability of the genotypes of common beans, cultivated in different environments through multivariate analysis of genotype performance employing up water contents, protein value and technological parameters of quality (percentage of absorption of water before and after cooking, time of cooking, percentage of complete grains, volumetric expansion and soluble solid totals in the broth), together with average productivity of the genotypes. To that end, 19 genotypes of common bean of the carioca and black commercial groups, belonging the testing of VCU (Value of Cultivation and Use) of São Paulo state have been evaluated in the crops of 2005/2006/2007. According to the results obtained by multivariate analysis for the set of the three seasons of culture the genotype Gen 96A98-15-3-52-1 and IAC- Alvorada were classified as stable, responsive to improvement of the environment, and tolerant in unfavorable environments. It can be concluded from these results that the univariate and multivariate adaptability and stability analyses proposed by Carneiro (1998) based on Lin \& Binns (1988) is an efficient and simple way to assess the genotype performance of the cultivars, besides presenting parameter uniqueness to estimate adaptability to favorable and unfavorable environments, with a simple interpretation of the results.
\end{abstract}

Index terms: Productivity, technological quality, value protein, genotype x environment interaction.

(Recebido em 22 de abril de 2008 e aprovado em 31 de julho de 2009)

\section{INTRODUÇÃO}

O feijão (Phaseolus vulgaris L.), além de fornecer nutrientes essenciais, representa uma importante fonte protéica na alimentação dos brasileiros, especialmente pelo menor custo de sua proteína em relação aos produtos de origem animal (Paula, 2004). No desenvolvimento de novas cultivares, características como: alta produtividade, resistência a fatores bióticos e abióticos são desejadas, porém, visando a atender as exigências do mercado consumidor, busca-se também melhoria nas qualidades tecnológicas e nutricionais dos grãos.

Para que uma cultivar de feijoeiro seja aceita no mercado deve apresentar características culinárias desejáveis, como rápida absorção de água, baixo tempo de cozimento e capacidade de produzir caldo claro e denso, após o cozimento(Mesquita et al., 2007; Coelho,

\footnotetext{
1Instituto Agronômico/APTA - Cx. P. 28 - 13012-970 - Campinas, SP - efperina@yahoo.com.br

IInstituto Agronômico - Campinas, SP

Instituto Agronômico/APTA - Campinas, SP
} 
S.R.M. et al., 2009). De acordo com Dalla Corte et al. (2003), a qualidade dos grãos para o cozimento é afetada por fatores climáticos, práticas de cultivo, beneficiamento pós-colheita e condições de armazenamento. Assim, a influência do ambiente que atua no desenvolvimento da semente durante o cultivo da planta contribui para a ocorrência de interação genótipo x ambiente nas características culinárias do feijão (Carbonell et al., 2003). Portanto, o conhecimento da estabilidade e adaptabilidade dos genótipos a determinados ambientes é importante, pois, permite a identificação de genótipos estáveis e adaptados às variações ambientais.

A análise da performance genotípica multivariada, pela estimativa do parâmetro de medida de adaptabilidade e estabilidade de comportamento (MAEC - multivariado), permite que a recomendação de cultivares seja feita com base em mais de um caráter de importância econômica para a cultura (Carneiro, 1998). Sabendo que a recomendação de uma nova cultivar não se baseia em apenas uma única variável, neste trabalho, objetivou-se avaliar a estabilidade e adaptabilidade dos genótipos de feijoeiro cultivados em diferentes ambientes, empregando a análise multivariada da performance genotípica. Para tanto, consideraram-se as características tecnológicas, o valor protéico, o teor de umidade dos grãos e a produtividade média dos genótipos.

\section{MATERIAL E MÉTODOS}

\section{Material Genético}

Foram avaliados 19 genótipos de feijoeiro de tegumento carioca e preto pertencentes aos principais Programas de Melhoramento de feijoeiro do país, sendo quatro linhagens da EMBRAPA (BRS-Pontal, BRSRequinte, BRS-Triunfo e BRS-Grafite), cinco do IAC (Gen 96A98-15-3-52-1, Gen 96A45-3-51-52-1, Gen 96A9813-1-52-1, Gen 96A98-5-1-1-55 e Gen 96A3-P1-1-1), quatro do IAPAR (LP 01-38, LP 9979, LP 98-122 e LP 02130) e duas linhagens da UFLA (CV-48 e Z-28) e as cultivares padrões IAC-Carioca Tybatã e Pérola, do grupo comercial carioca e, IAC-Una e FT-Nobre, do grupo comercial preto. Os ensaios de competição de linhagens e cultivares de feijoeiro (VCU- Valor de Cultivo e Uso) seguiram as normas do MAPA-SNPC (Ministério da Agricultura, Pecuária e Abastecimento/Serviço Nacional de Proteção de Cultivares) e foram semeados em 18 ambientes no estado de São Paulo, nas três épocas de semeadura (águas, seca e inverno). Os locais e épocas de semeadura utilizados na condução dos ensaios estão descritos na Tabela 1 .

\section{Avaliações agronômicas, tecnológicas, valor protéico e} umidade dos grãos

A determinação da porcentagem de embebição de água antes do cozimento (PEANC) e após o cozimento dos grãos (PEAPC) foi baseada na aplicação dos métodos descritos nos artigos científicos de Garcia-Vela \& Stanley (1989) e Plhak et al., (1989). A porcentagem de grãos inteiros (PGI) foi realizada com as mesmas amostras de grãos utilizadas para determinar a porcentagem de embebição de água após o cozimento. Os grãos, após o cozimento, foram drenados e separados em duas porções: inteiros e partidos, quantificando assim a porcentagem de grãos inteiros. A análise para determinação do tempo de cozimento (TC) foi realizada seguindo o método adaptado dos propostos por Sartori (1982) e Proctor \& Watts (1987). A taxa de expansão volumétrica foi determinada seguindo o método adaptado do proposto por (Martin-Cabrejas et al., 1997). Os grãos, também foram avaliados quanto aos teores de umidade (UM), segundo o método descrito pela AOAC (1998), enquanto que as análises de proteína bruta foram realizadas utilizando-se o método microKjeldhal, descrito em Bataglia et al. (1983), convertendo-se o teor de nitrogênio para proteína total $(\% \mathrm{~N}$ x 6,25). Os sólidos solúveis totais no caldo (SSTc) dos grãos de feijão, foram determinados, baseando-se na metodologia descrita por Sartori (1982). As avaliações analíticas das qualidades tecnológica e nutricional foram efetuadas em sementes com até 60 dias depois de colhidas, uniformizadas por peneiras de classificação (peneira 13) e pré-analisadas para a retirada de sementes visualmente danificadas por insetos ou dano mecânico. As avaliações tecnológicas dos grãos foram realizadas em triplicata, enquanto que as avaliações químicas foram determinadas com duas repetições analíticas Neste trabalho, determinou-se também a produtividade média (PROD) de cada genótipo por meio de três repetições de campo.

\section{Análises Estatísticas dos Dados}

Os dados da qualidade tecnológica e nutricional dos grãos foram submetidos a análise de variância (ANAVA), e foi calculado o coeficiente de variação para as épocas das águas, da seca, de inverno e para o conjunto das três épocas, no modelo inteiramente casualizado. Para comparação entre as médias dos genótipos avaliados em relação ao melhor cultivar-padrão utilizou-se o teste de Dunnett (5\%). Essas análises foram efetuadas com o auxilio do programa SAS (Statistical Analysis System).

Considerando que a indicação de uma cultivar não é feita com base em apenas uma única variável, foi adotado o método das diferenças em relação à reta bissegmentada 
ponderada pelo coeficiente de variação (CV) multivariado, proposto por (Carneiro, 1998). O genótipo hipotético foi definido de acordo com o modelo proposto por (Cruz et al., 1989), como a seguir: $X_{m j}=b_{0 m}+b_{1 m} I j+$ $\mathrm{b}_{2 \mathrm{~m}} \mathrm{~T}\left(\mathrm{I}_{\mathrm{j}}\right)$, em que, $\mathrm{X}_{\mathrm{mj}}$ : é a resposta ideal do genótipo hipotético no ambiente $\mathrm{j} ; \mathrm{b}_{0 \mathrm{~m}}$ : é o valor fornecido para que a resposta ideal seja máxima para todos os locais; $b_{1 \mathrm{~m}} \mathrm{e}$ $\mathrm{b}_{2 \mathrm{~m}}$ : coeficientes de regressão linear, cujos valores são atribuídos para que haja resposta próxima do ideal; Ij: é o índice de ambiente codificado.

No presente trabalho, foi estabelecido $b_{0 \mathrm{~m}}$ igual ao valor máximo obtido pela variável para cada experimento. Foram também atribuídos aos coeficientes de regressão linear os valores de: $b_{1 \mathrm{~m}}=0,5$ (baixa resposta aos ambientes desfavoráveis) e $b_{2 m}=1,0$ (responsivo às condições favoráveis), ou seja, considerou-se um genótipo com baixa resposta nos ambientes desfavoráveis $\left(b_{1 \mathrm{~m}}=0,5\right)$ e responsivos nos ambientes favoráveis $\left(\mathrm{b}_{1 \mathrm{~m}+} \mathrm{b}_{2 \mathrm{~m}}=1,5\right)$.

Para a realização da análise multivariada daperformance genotípica $\left(\mathrm{P}_{\mathrm{mi}}\right)$, há uma necessidade de padronizar os $\mathrm{P}_{\mathrm{i}}$ 's e atribuir um fator de multiplicação dado pelo inverso dos pesos atribuídos a cada variável, a fim de balancear a importância de cada variável. Desse modo, o estimador do parâmetro MAEC passa a ser dado pela equação:

$$
P_{m i}=\sum_{k=1}^{v}\left[P_{i k} \frac{1}{\hat{\sigma}_{p k}}\right] \times \frac{1}{p_{k}}
$$

Em que:

$\mathrm{P}_{\mathrm{mi}}$ : é o estimador do parâmetro MAEC - multivariado para a cultivar $\mathrm{i} ; \mathrm{P}_{\mathrm{ik}}$ : é o estimador do parâmetro MAEC para a cultivar i relativo a k-ésima variável; $\mathrm{K}=1,2,3, \ldots, \mathrm{v} ; \hat{\sigma}_{\mathrm{pk}}$ é o desvio-padrão dos $\mathrm{P}_{\mathrm{i}}$ 's para a k-ésima variável; e, $\mathrm{p}_{\mathrm{k}}=$ representa os pesos atribuídos, a cada variável.

Neste trabalho, para as variáveis PEANC, TC, PGI, PROD, SSTc e PB adotou-se peso igual a um e para as variáveis PEAPC, EV e UM, peso igual a dois. As estimativas dos parâmetros de adaptabilidade e estabilidade geral $\left(\mathrm{P}_{\text {mig }}\right)$, bem como, os parâmetros de adaptabilidade e estabilidade específica a ambientes favoráveis $\left(\mathrm{P}_{\text {mif }}\right)$ (ambiente com média superior a média geral) e desfavoráveis $\left(\mathrm{P}_{\text {mid }}\right)$ (ambiente com média inferior a média geral), foram realizados pelo Programa Computacional GENES (Cruz, 2006), na qual utiliza em sua programação a metodologia proposta por (Carneiro 1998).

Assim, os genótipos com menores valores de $\mathrm{P}\left({ }_{\text {mig }}\right)$, $\mathrm{P}\left({ }_{\text {mif }}\right)$ e $\mathrm{P}\left({ }_{\text {mid }}\right)$ apresentam comportamento mais próximo ao do genótipo hipotético ideal, indicando a superioridade geral e específica (ambientes favoráveis e desfavoráveis) do genótipo em questão.

\section{RESULTADOS E DISCUSSÃO}

Os caracteres absorção de água antes do cozimento (PEANC), absorção de água após o cozimento (PEAPC), tempo de cozimento (TC), porcentagem de grãos inteiros (PGI), expansão volumétrica (EV), sólidos solúveis totais no caldo após o cozimento (SSTc), produtividade (PROD), proteína bruta (PB) e umidade (UM), apresentaram efeito significativo de ambiente, genótipo e interação genótipo ambiente ao nível de $1 \%$ e $5 \%$ de probabilidade pelo teste $\mathrm{F}$, indicando a existência de diferenças genéticas e ambientais nas cultivares e linhagens de feijão avaliadas.

$\mathrm{Na}$ Tabela 2, reportam-se os resultados obtidos na análise dos genótipos cultivados nas épocas das águas, da seca, de inverno e no conjunto das três épocas de semeadura. Ao compararmos as médias obtidas entre as épocas de cultivo (águas, seca e inverno), observou-se que a capacidade de absorção de água antes do cozimento (PEANC) variou de 102,18\% (época da seca) a 104,71\% (época das águas), destacando-se as cultivares Gen 96A9815-3-52-1(época das águas, da seca e análise conjunta) e LP 01-38 (época de inverno), por apresentarem os maiores valores de PEANC. Alguns autores sugerem a utilização da absorção de água do grão antes do cozimento como um indicativo do tempo de cozimento em razão da observação de correlação positiva entre esses caracteres (Costa et al.,

Tabela 1 - Locais e épocas de semeadura utilizados para a condução dos ensaios regionais de valor de cultivo e uso (VCU) no estado de São Paulo.

\begin{tabular}{|c|c|c|c|c|c|}
\hline \multicolumn{6}{|c|}{ Épocas de semeadura } \\
\hline Águas/2005 & Seca/2006 & Inverno/2006 & Águas/2006 & Seca/2007 & Inverno/2007 \\
\hline Tatuí & Avaré & Colina & Mococa & Avaré & Colina \\
\hline $\begin{array}{c}\text { Monte Alegre } \\
\text { do Sul }\end{array}$ & Capão Bonito & Fernandópolis & Capão Bonito & $\begin{array}{c}\text { Monte Alegre } \\
\text { do Sul }\end{array}$ & Mococa \\
\hline Mococa & Mococa & Ribeirão Preto & Avaré & Tatuí & Araras \\
\hline
\end{tabular}


2001; Dalla Corte et al., 2003). Entretanto, Carbonell et al. (2003)Coelho et al. (2008), não encontraram correlação positiva entre esses caracteres e sugeriram que, seleções de genótipos com base na utilização do teste de absorção de água pelos grãos como indicativo do tempo de cozimento, são pouco expressivas e nem sempre confiáveis, decorrente da baixa correlação encontrada.

Para a característica absorção de água após o cozimento (PEANC), observou-se variação de $138,74 \%$ (época das águas) a 145,11\% (época da seca), os genótipos que apresentaram alta absorção de água após o cozimento foram: IAC-Alvorada (época das águas e análise conjunta), Gen 96A98-15-3-52-1 (época da seca) e LP 01-38 (época de inverno). Grãos de feijão com altos valores de PEAPC são recomendados a refeitórios e cozinhas industriais, pois, proporcionam maior rendimento após o seu cozimento.

Entre as características tecnológicas avaliadas nos grãos de feijão, o tempo de cozimento de uma cultivar é determinante para a sua aceitação pelo consumidor. Nos genótipos avaliados, o tempo de cozimento (TC) variou de 26'15" (época das águas) a 34'27" (época de inverno), sendo que as cultivares e linhagens IAC-Alvorada (época das águas e seca) e Gen 96A98-15-3-52-1(época de inverno e análise conjunta) tiveram o menor tempo de cozimento (Tabela 2). Além das diferenças genéticas presentes nos genótipos, o tempo de cozimento também é influenciado pelo local de cultivo e pela interação genótipo por ambiente (Carbonell et al., 2003; Dalla Corte et al., 2003).

A porcentagem de grãos inteiros (PGI) nas amostras avaliadas variou de $35,89 \%$ (época da seca) a $47,13 \%$ (época das águas). Os genótipos do grupo comercial preto apresentaram maior porcentagem de grãos inteiros (PGI). A presença de grãos inteiros é um aspecto desejável na industrialização do feijão.

Com base nos resultados da tabela 2, observou-se que na época das águas, o teor de sólidos solúveis totais no caldo foi de $10,72 \%$, provavelmente porque o tempo de cozimento foi reduzido e a porcentagem de grãos inteiros superior, não permitindo a liberação dos sólidos solúveis para o caldo. Já, em relação à época de inverno, onde o teor de sólidos solúveis foi maior $(11,96 \%)$, houve aumento no tempo de cozimento e redução na porcentagem de grãos inteiros. Assim, o aumento do tempo de permanência dos grãos cozinhando pode ter favorecido o aumento do teor de SST . Na época da seca, embora o tempo de cozimento tenha sido superior ao das águas, o teor de sólidos solúveis totais no caldo foi de $11,57 \%$; resultado que pode ser explicado pela porcentagem maior de grãos partidos $(64,11 \%)$, o que teria facilitado a liberação dos sólidos solúveis para o caldo. De forma geral, o teor de sólidos totais no caldo, pode ser influenciado pelo tempo de cozimento e porcentagem de grãos inteiros.

Em relação aos resultados obtidos para o teor de proteína bruta nos grãos (Tabela 3), observou-se que a época da seca propiciou resultados médios maiores para o teor de proteína bruta $(22,93 \%)$, em relação à época de inverno $(21,35 \%)$ e das águas $(21,23 \%)$. Esses resultados corroboram com Lajolo et al. (1996), que afirmaram haver variações na composição de proteína do feijão em função do local de cultivo, condições climáticas e da própria cultivar.

Para obter materiais realmente superiores, é necessário que o material selecionado reúna, simultaneamente, uma série de atributos favoráveis que lhe confira rendimento comparativo mais elevado e que satisfaça tanto as exigências do consumidor quanto as do produtor. A seleção com base em uma, ou em poucas características, tem se mostrado inadequada, por conduzir a um produto final superior em relação apenas aos caracteres selecionados, mas com desempenho não tão favorável em relação aos vários outros caracteres não considerados durante a prática seletiva (Cruz, 2006). Assim, uma maneira de se aumentar a chance do êxito de um programa de melhoramento é a utilização da análise multivariada da performance genotípica, pois reúne, em um único parâmetro, todos os requisitos exigidos para a recomendação de novas cultivares.

Considerando os resultados obtidos pela análise multivariada para o conjunto das três épocas de semeadura (Tabela 4), o genótipo BRS-Grafite apresentou o melhor desempenho para as condições gerais, e também se posicionou entre os primeiros colocados para os ambientes favoráveis. Essa classificação pode ser atribuída, em parte, ao bom desempenho médio do genótipo para algumas das variáveis estudadas. Já, a linhagem Gen 96A98-15-3-52-1 e a cultivar IAC-Alvorada apresentaram performance superior às demais, para as condições gerais, favoráveis e desfavoráveis, segundo o procedimento da análise multivariada, assim como, para a maioria dos caracteres avaliados individualmente, mostrando que estas variáveis pesaram na classificação multivariada dos genótipos, assim como os pesos atribuídos a elas.

De acordo com os resultados obtidos por meio da análise multivariada da performance genotípica, é possível dizer que a linhagem Gen 96A98-15-3-52-1 e a cultivar IAC-Alvorada estão próximas dos resultados buscados pelos melhoristas e produtores, pois, são materiais estáveis e adaptados aos ambientes favoráveis e desfavoráveis. Além disso, atendem às exigências dos consumidores, uma vez, que possuem bom conteúdo protéico, menor tempo de cozimento dentre outras características culinárias de importância. 


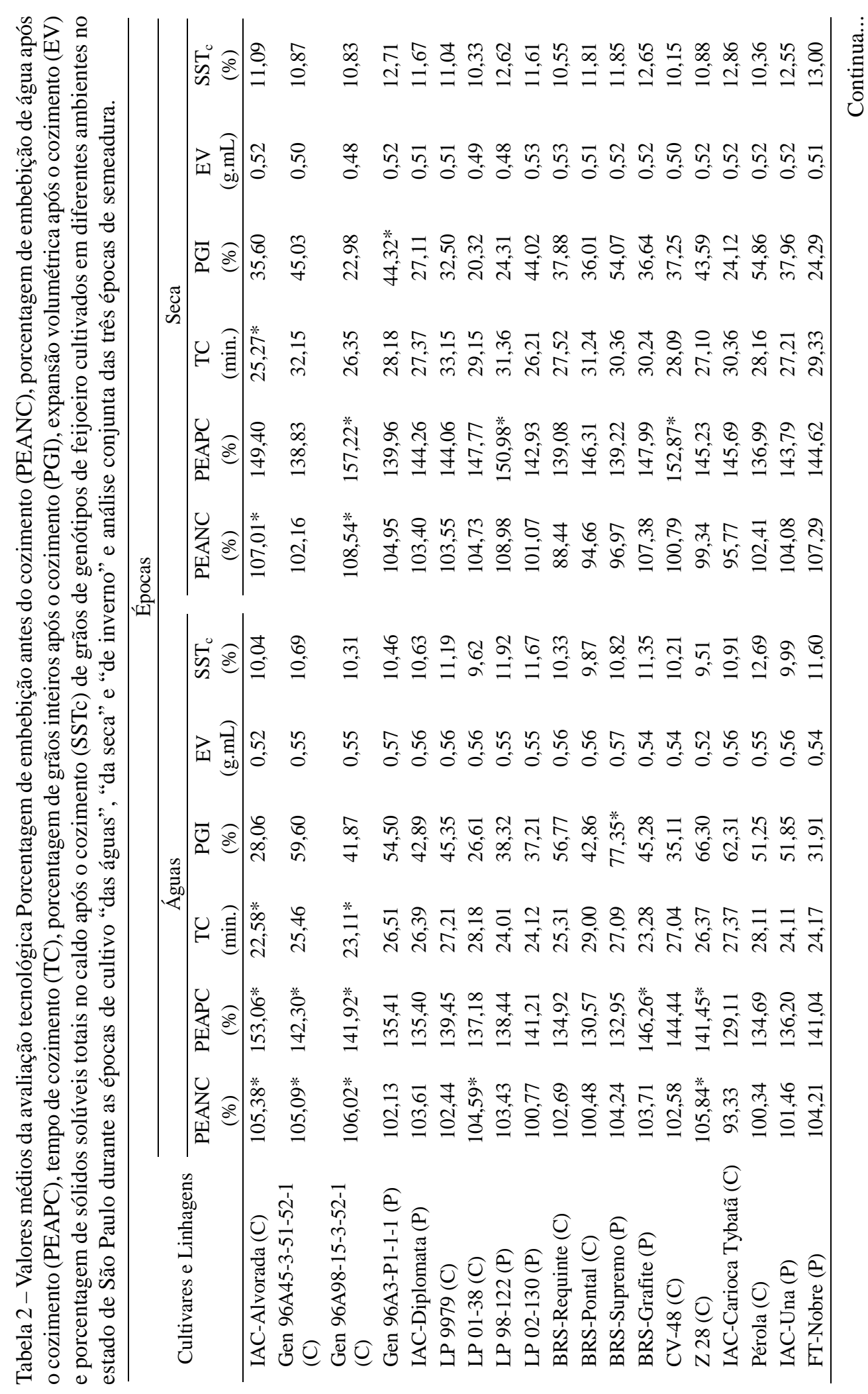

Ciênc. agrotec., Lavras, v. 34, n. 2, p. 398-406, mar./abr., 2010 


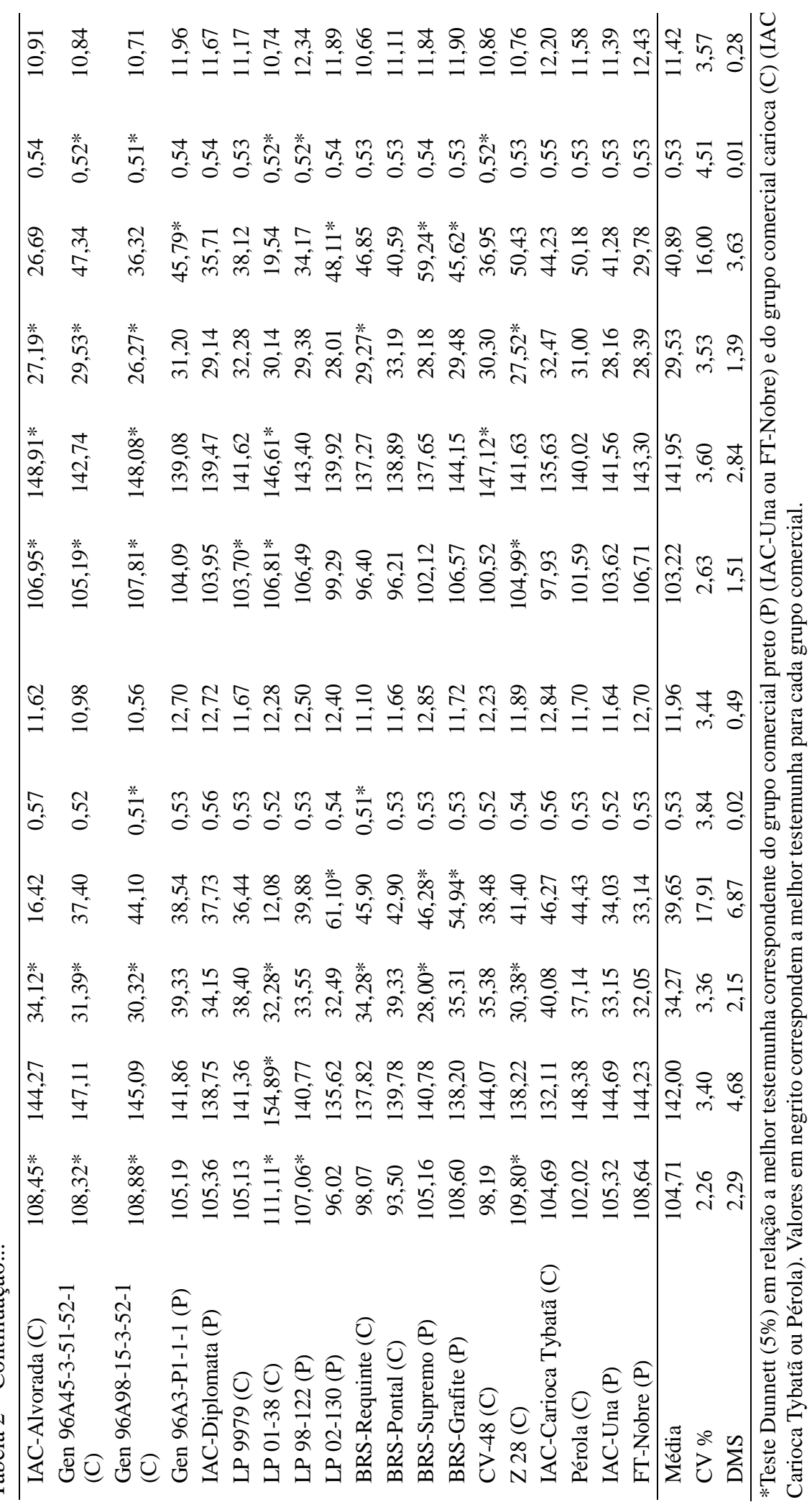

Ciênc. agrotec., Lavras, v. 34, n. 2, p. 398-406, mar./abr., 2010 


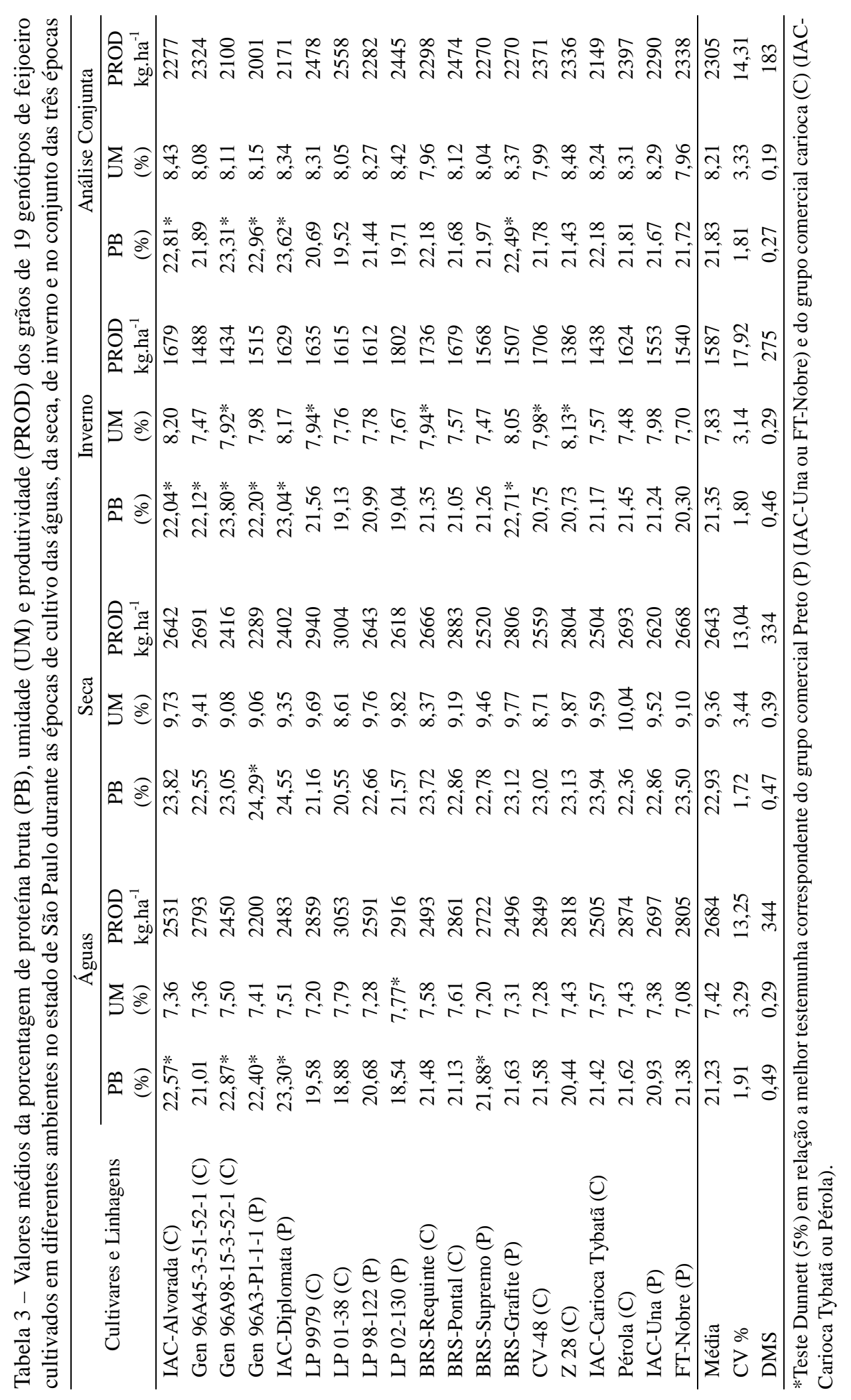

Ciênc. agrotec., Lavras, v. 34, n. 2, p. 398-406, mar./abr., 2010 
Tabela 4 - Estimativas dos parâmetros de estabilidade e adaptabilidade multivariada para condições geral $\left(\mathrm{P}_{\text {mig }}\right)$, favorável $\left(\mathrm{P}_{\text {mif }}\right)$, desfavorável $\left(\mathrm{P}_{\text {mid }}\right)$, segundo a metodologia de Lin \& Binns (1988), modificada por Carneiro (1998), de 19 genótipos de feijoeiro cultivados conjunto das três épocas de semeadura (águas, seca e inverno) para o estado de São Paulo.

\begin{tabular}{|c|c|c|c|c|}
\hline \multirow{2}{*}{ Cultivares e Linhagens } & \multicolumn{4}{|c|}{ Análise Conjunta } \\
\hline & Média & $P_{\text {mig }}$ & $\mathrm{P}_{\text {mif }}$ & $\mathrm{P}_{\text {mid }}$ \\
\hline IAC-Alvorada (C) & 23,21 & 1,6 & 1,7 & 1,5 \\
\hline Gen 96A45-3-51-52-1 (C) & 22,29 & 1,7 & 1,9 & 1,7 \\
\hline Gen 96A98-15-3-52-1 (C) & 23,24 & 1,6 & 1,7 & 1,5 \\
\hline Gen 96A3-P1-1-1 (P) & 23,36 & 1,7 & 1,9 & 1,7 \\
\hline IAC-Diplomata (P) & 23,23 & 1,6 & 1,8 & 1,6 \\
\hline LP 9979 (C) & 21,16 & 1,8 & 2,2 & 1,9 \\
\hline LP 01-38 (C) & 19,52 & 1,9 & 2,2 & 1,9 \\
\hline LP 98-122(P) & 21,44 & 1,7 & 2,0 & 1,7 \\
\hline LP 02-130 (P) & 20,12 & 1,8 & 2,3 & 1,9 \\
\hline BRS-Requinte (C) & 22,18 & 1,9 & 2,2 & 2,0 \\
\hline BRS-Pontal (C) & 22,08 & 2,0 & 2,3 & 2,1 \\
\hline BRS-Supremo (P) & 22,37 & 1,6 & 1,8 & 1,5 \\
\hline BRS-Grafite (P) & 22,49 & 1,6 & 1,8 & 1,6 \\
\hline CV-48 (C) & 22,18 & 1,8 & 2,1 & 1,8 \\
\hline Z $28(C)$ & 21,43 & 1,6 & 1,8 & 1,6 \\
\hline IAC-Carioca Tybatã (C) & 22,18 & 1,9 & 2,0 & 1,8 \\
\hline Pérola (C) & 22,21 & 1,7 & 1,9 & 1,6 \\
\hline IAC-Una (P) & 22,08 & 1,7 & 1,8 & 1,6 \\
\hline FT-Nobre (P) & 22,13 & 1,6 & 1,8 & 1,6 \\
\hline
\end{tabular}

*Valores médios de PEANC, PEAPC, TC, PGI, EV, SSTc, PB, UM e Produtividade de cada genótipo de feijoeiro cultivados em diferentes ambientes no estado de São Paulo durante as épocas de semeadura das águas, da seca e de inverno e no conjunto das três épocas de semeadura multiplicados pelos seus respectivos pesos.

O uso do método multivariado da performance genotípica, é promissor nos programas de melhoramento, pois reúne, em um único parâmetro, todos os requisitos exigidos para a recomendação de novas cultivares. No entanto, para o uso correto dessa metodologia, são necessários melhores conhecimentos da contribuição que cada variável exerce no objetivo final dos programas de melhoramento, e, consequentemente, dos pesos adotados para cada uma delas, uma vez que esses valores são atribuídos pela vivência prática dos melhoristas.

\section{CONCLUSÃO}

A partir dos resultados obtidos, pode-se concluir que os genótipos IAC-Alvorada e Gen96A98-15-3-52-1 apresentaram bom desempenho para condições de $\mathrm{P}_{\mathrm{mi}}$ (geral, favorável e desfavorável) para o conjunto das três épocas de semeadura.

Esta análise permitiu, melhores esclarecimentos da performance dos genótipos, pois vários caracteres foram simultaneamente avaliados.

\section{AGRADECIMENTOS}

FAPESP e CNPq pelo apoio financeiro e ao DDD/ Apta Regional pela instalação dos ensaios de VCU nos Pólos Regionais de Desenvolvimento Científico e Tecnológico.

\section{REFERÊNCIAS BIBLIOGRÁFICAS}

ASSOCIATION OF OFFICIAL ANALYTICAL CHEMIST. Official methods of analysis. 16.ed. Washington, 1998. 1170p.

BATAGLIA, O.C.; FURLANI, A.M.C.; TEIXEIRA, J.P.F.; FURLANI, P.R.; GALLO, J.R. Métodos de análise química de plantas. Campinas: Instituto Agronômico, 1983. 48p. (Boletim Técnico, 78).

CARBONELL, S.A.M.; CARVALHO, C.R.L.; PEREIRA, V.R. Qualidade tecnológica de grãos de genótipos de feijoeiro cultivados em diferentes ambientes. Bragantia, Campinas, v.62, n.3, p.369-379, 2003. 
CARNEIRO, P.C.S. Novas metodologias de análise da adaptabilidade e estabilidade de comportamento. 1998. 155p. Dissertação (Doutorado em Genética e Melhoramento)-Universidade Federal de Viçosa, Viçosa, 1998.

COELHO, C. M. M.; SOUZA, C. A.; DANELLI, A. L. D.; PEREIRA, T.; SANTOS, J. C. P.; PIAZZOLI, D.

Capacidade de cocção de grãos de feijão em função do genótipo e da temperatura da água de hidratação.

Ciência e Agrotecnologia. Lavras, v.32, n. 4, p. 10801086, jul./ago., 2008.

COELHO, S. R. M.; PRUDENCIO, S. H.; NÓBREGA, L. H. P.; LEITE, C. F. R. Alterações no tempo de cozimento e textura dos grãos de feijão comum durante $o$ armazenamento. Ciência e Agrotecnologia. Lavras, v.33, n. 2, p. 539-544, mar./abr., 2009.

CRUZ, C.D. Programa Genes: biometria. Viçosa, MG: UFV, 2006. 107p.

CRUZ, C.D.; TORRES, R.A. de.; VENCOVSKY, R. Na alternative approach to the stability analysis proposed by Silva e Barreto. Revista Brasileira de Genética, Ribeirão Preto, v.12, p.567-580, 1989.

DALLA CORTE, A.; MODA-CIRINO, V.; SCHOLZ, M.B.S.; DESTRO, D. Environment effect on grain quality in early common bean cultivars and lines. Crop Breeding and Applied Biotechnology, Maringá, v.3, n.3, p.193-202, 2003.

GARCIA-VELA, L.A.; STANLEY, D.W. Water-holding capacity in hard-to-cook bean (P. vulgaris L.): effect of $\mathrm{pH}$ and ionic strength. Journal of Food Science, Chicago, v.54, n.4, p.1080-1081, 1989.

LAJOLO, F.M.; GENOVESE, M.I.; MENEZES, E.W. Qualidade nutricional. In: ARAUJO, R.S.; RAVA, C.A.; STONE, L.F.; ZIMMERMANN, M.J.O. Cultura do feijoeiro comum no Brasil. Piracicaba: Potafos, 1996. p.23-56.
LIN, C.S.; BINNS, M.R. A superiority measure of cultivar performance for cultivar $\mathrm{x}$ location data. Canadian Journal of Plant Science, Ottawa, v.68, n.3, p.193-198, 1988.

MARTIN-CABREJAS, M.A.; ESTEBAN, R.M.; PEREZ, P.; MAINA, G.; WALDRON, K.W. Changes in psyscochimical properties of dry beans (Phaseolus vulgaris $\mathrm{L}$.) during long term storage. Journal of Agricultural and Food Chemistry, Washington, v.47, p.3223-3227, 1997.

MESQUITA, F. R.; CORRÊA, A.D.; ABREU, C. M. P. de; LIMA, R. A. Z.; ABREU, A. de F. B. Linhagens de feijão (Phaseolus vulgaris, L.): Composição química $\mathrm{e}$ digestibilidade protéica. Ciência e Agrotecnologia, Lavras, v.31, n. 4, p.1114-1121, jul./ago., 2007.

MURAKAMI, D.M.; CARDOSO, A.A.; CRUZ, C.D.; BIZÃO, N. Considerações sobre duas metodologias de análise de estabilidade e adaptabilidade. Ciência Rural, Santa Maria, v.34, n. 1, p.71-78, jan./fev. 2004.

PAULA, S.R.R. Efeito materno associado à capacidade de cozimento do feijoeiro. 2004. 53p. Dissertação (Mestrado em Genética e Melhoramento de Vegetal)-Universidade Federal de Lavras, Lavras, 2004.

PLHAK, L.C.; CALDWELL, K.B.; STANLEY, D.W. Comparision of methods used to characterize water imbibition in hard-tocook beans. Journal of Food Science, Chicago, v.54, n.3, p.326-336, 1989.

PROCTOR, J.R.; WATTS, B.M. Development of a modified mattson bean cooker produre based on sensory panel cookability evaluation. Canadian Institute of Food Science and Tecnology, Ottowa, v.20, n.1, p.9-14, Feb. 1987.

SARTORI, M.R. Technological quality of dry beans (Phaseolus vulgaris) stored under nitrogen. 1982. Thesis (Ph.D.)-Kansas State University, Manhattan, 1982. 